\title{
Can FRAX Tool be Used for Determination of Risk Score for Osteoporosis Fractures in a Financially Constrained Society Like Bangladesh?
}

\author{
Akter Na, Qureshi NK ${ }^{\mathrm{b}}$, Latif ZA ${ }^{\mathrm{c}}$
}

\begin{abstract}
Background: This study was designed to assess the effectiveness of use of the fracture risk assessment system (FRAX) as risk assessment tool for osteoporosis risk score scale in Bangladeshi subjects and to assess how the results of the tools correlate with each other.

Methods: This cross-sectional study was conducted between January 2016 to August 2016. The study population was randomly collected 600 Bangladeshi subjects; who attended outpatient department (OPD) of MARKS Medical College \& Hospital, Dhaka, Bangladesh. The age range of the subjects was between 40 to 75 years. The subjects had not done a bone mineral density (BMD) score. None of them were previously diagnosed or got treatment for osteoporosis. A questionnaire was designed to complete the osteoporosis specific risk score sheet. Major osteoporotic and hip fracture incidence to 10-years as a function of the FRAX probability was calculated by using fracture risk assessment system.

Results: A total of 600 subjects were included. Among them, $59.2 \%$ and $40.8 \%$ were male and female respectively. Mean age (Mean $\pm S D)$ of the study, subjects were 52.16 7.96 years. Among study subjects, mean BMI was more in females in comparison to males $(p<0.05)$. The FRAX predicted 10-year risk assessment scores of major osteoporotic fractures were significantly more in females than males $(p<0.02)$. Risk assessment scores of both major osteoporotic fractures and hip fractures showed significant association in post-menopausal women when compared with there who were not menopausal $(p<0.05)$. Risk assessment factors for risk scores did differ significantly among male and female subjects and among postmenopausal and non-menopausal women. Among risk assessment factors, subjects having finally history of fracture hip, glucocorticoids, rheumatoid arthritis showed strong association with presence of $\geq 20 \%$ risk scores for major osteoporotic fracture $(p<0.05)$ and $\geq 3 \%$ for hip fracture $(p<0.05)$. Subjects having history of previous fracture and secondary osteoporosis showed only significant association with $\geq 3 \%$ risk scores for hip fracture $(p<0.05)$.

Conclusion: The public health burden of fractures will fail to compromise unless the subset of patients who are at increased risk for fracture are identified and treated. Ten-year fracture risk assessment with the fracture risk assessment system is increasingly used to guide for treatment decisions. It is an effective tool to predict fracture probability, particularly in developing countries like Bangladesh, where most of the patients cannot afford expensive dual energy $x$-ray absorptiometry scans.
\end{abstract}

Key words: FRAX, Risk Assessment Tools, Osteoporosis.

(BIRDEM Med J 2018; 8(1): 9-15)

\begin{abstract}
Author Information
a. Dr. Nazma Akter, Resident Physician \& Consultant (Endocrinology \& Metabolism), MARKS Medical College \& Hospital, Dhaka, Bangladesh.

b. Dr. Nazmul Kabir Qureshi, Consultant (Endocrinology \& Metabolism), National Health Care Network (NHN), DAB, Bangladesh.

c. Prof. Dr. Zafar Ahmed Latif, Professor of Endocrinology \& Metabolism, BIRDEM \& IMC, Dhaka, Bangladesh.

Address of Correspondence: Dr. Nazma Akter, Resident Physician \& Consultant (Endocrinology \& Metabolism), MARKS Medical College \& Hospital, Dhaka, Bangladesh. E-mail: nazma_aktar_endo@yahoo.com
\end{abstract}

Received: August 12, 2017

Accepted: October 31, 2017

\section{Introduction}

Osteoporosis is a progressive bone disease characterized by a decrease in bone mass with micro-architectural change. When bone strength is reduced, it can lead to an increased risk of osteoporotic fracture. Osteoporotic fracture is an important disease in terms of health and economic aspects as it can deteriorate the quality of life by disabling the individual but also can increase the risk of early death. ${ }^{1-4}$ The disease is identified clinically by the occurrence of non-traumatic fractures, especially in the lumbar spine (vertebral fractures) and forearm and by the occurrence of femoral fractures after fall from 
height. The greatest loss of bone mass occurs in women during perimenopause and is associated with estrogen insufficiency, a condition of menopause. ${ }^{5}$ Osteoporosis and its consequent increase in fracture risk is a major health concern for postmenopausal women and older men and has the potential to reach epidemic proportions. ${ }^{6}$ Osteoporosis is diagnosed by measuring BMD. Commencement of treatment is also based on the T-score of BMD. However, the absolute frequency of osteoporotic fracture is higher in patients with osteopenia than in patients with osteoporosis, therefore starting treatment based on $\mathrm{T}$ score (T-score $<-2.5$ ) is problematic because the treatment timing may be delayed for many patients with fractures. This delay likely increases individual prevalence as well as mortality in addition to increasing the medical cost of the whole ${ }^{7}$. To this end, new standards have been required for early detection and treatment of osteoporotic fracture.

The WHO fracture risk assessment tool is an internetbased fracture prediction tool developed by the World Health Organization Collaborating Centre for Metabolic Bone Diseases at Sheffield University, UK. FRAX is used to calculate the 10-year probability of hip fracture risk as well as the 10-year probability of a major osteoporotic fracture. The calculation can be performed by entering 12 risk factors including nationality, gender, age, weight, height and BMD (with or without) into the FRAX web site. However, the diagnostic threshold has not yet been established and the study is still in progress. ${ }^{8}$ FRAX is increasingly being used to guide treatment decisions. It is an effective tool, particularly in developing countries like Bangladesh to be utilized as prediction factor of osteoporotic fracture. This study was designed to assess the effectiveness of use of FRAX as risk assessment tools for osteoporosis risk score sheet in Bangladeshi subjects and how the results of the tools correlate with each other.

\section{Methods}

\section{Study Population}

The cross-sectional study was conducted among randomly sampled 600 Bangladeshi subjects. The study was carried out in the outpatient department (OPD) of Medicine, MARKS Medical College \& Hospital, a tertiary care hospital in Dhaka, Bangladesh from January 2016 to August 2016. The age range of the subjects was between 40 to 75 years. None of them were previously diagnosed or got treatment for osteoporosis. With written informed consent, a questionnaire was designed to complete the osteoporosis specific risk score sheet. The cases with factors likely to affect fracture severity such as those with past history of major trauma, past history of vertebral surgery and those with suspected vertebral metastasis caused by malignant tumor were excluded from the study. BMI (Body Mass Index) $(\mathrm{kg} /$ $\mathrm{m}^{2}$ ) was determined. The subjects had nota BMD score. Major osteoporotic and hip fracture incidence to 10years as a function of the FRAX probability was calculated by using FRAX risk score calculation page. ${ }^{8}$

\section{Methods of Calculation of FRAX Risk Score}

Information was collected for calculation of the FRAX risk score, including gender, age, weight, height, past history of fracture, parental history of hip fracture, current smoking status, history of using steroid rheumatoid arthritis, secondary osteoporosis, alcohol consumption e" 3 units/day. The collected data were entered into the calculation page of the Sheffield University $^{8}$ website to determine the FRAX risk score, i.e. the 10-year probability of a major osteoporotic fracture and the 10-year probability of hip fracture risk without information on bone density. As Bangladesh has yet not developed own version of country specific calculation tool; nearest country specific calculation tool of India for calculation the FRAX risk score was used. National Osteoporosis Foundation Guide (NOFG) recommends treating patients with FRAX 10-year risk scores of e" $3 \%$ for hip fracture or e" $20 \%$ for major osteoporotic fracture, to reduce their fracture risk. ${ }^{9} \mathrm{As}$ per NOFG recommendation, the frequency FRAX 10year risk scores of e" $3 \%$ for hip fracture or e" $20 \%$ for major osteoporotic fracture among different study groups were calculated before planning treatment for the patient.

\section{Component of FRAX Risk Score}

The risk factors used are the following: age, sex, weight $(\mathrm{kg})$, height $(\mathrm{cm})$, previous fracture, history of hip fracture in the patient's mother or father, Current smoking, glucocorticoids, rheumatoid arthritis, secondary osteoporosis, alcohol 3 or more units/day, with or without bone mineral density. The age range of the subjects was between 40 to 75 years. The history of glucocorticoid for patient was taken positive; if they were currently exposed to oral glucocorticoids or had 
been exposed to oral glucocorticoids for more than 3 months at a dose of prednisolone of $5 \mathrm{mg}$ daily or more or equivalent doses of other glucocorticoids. Due to socio-religious status of our country, most of the subjects were non-alcoholic. So, we did not consider the alcohol intake as a significant indicator of FRAX predicted risk score for our study population. And also most of our female subjects are non smoker. So difference between male and female subjects for history of current smoking was not taken as significant. For the clinical risk factors a 'yes' or 'no' response was asked for. If the field is left blank, then a "no" response is assumed by the calculator. A previous fracture denotes more accurately a previous fracture in adult life occurring spontaneously, or a fracture arising from trauma which, in a healthy individual, would not have resulted in a fracture. Secondary osteoporosis included type 1 diabetes, osteogenesis imperfecta in adults, untreated longstanding hyperthyroidism, hypogonadism or premature menopause $(<45$ years), chronic malnutrition or malabsorption and chronic liver disease.

\section{Statistical Analysis}

Data were analyzed with Statistical Package for Social Science (SPSS) software version 16. The means and standard deviations were used to describe continuous data. For categorical data, frequencies and percentages were estimated. Among the basic characteristics of the study subjects, the continuous variables were compared with each other using the Student's t-test. Categorical variables were compared with each other using the chisquare test. $P$ value $<0.05$ was considered as significant.

\section{Results}

A total of 600 subjects were included. Among them male and female were $59.2 \%$ and $40.8 \%$ respectively. The mean $( \pm \mathrm{SD})$ age of the study subjects were $52.16 \pm 7.96$ years. Maximum age was 75 years and minimum was 40 years. The mean $( \pm \mathrm{SD})$ age of the male and female were $52.91 \pm 8.20$ and $51.08 \pm 7.50$ years respectively $(\mathrm{p}<0.05)$. The mean height (meter) and weight $(\mathrm{kg})$ were higher in male subjects than female (1.62 \pm 7.36 vs. $1.53 \pm 6.88$ and $65.64 \pm 7.64$ vs. $60.36 \pm 8.29$ respectively). Average BMI $\left(\mathrm{mg} / \mathrm{m}^{2}\right)$ was more and showed significant association with female than male subjects $(25.58 \pm 3.79$ vs. $24.70 \pm 2.76 ; \mathrm{p}<0.05)$. The FRAX predicted 10-year risk assessment scores of major osteoporotic fracture were significantly more in female subjects than males $(p<0.02)$. Among male and female subjects, the mean FRAX predicted 10 -year risk scores of major osteoporotic fracture and hip fracture were $2.64 \pm 2.64$ vs. $3.28 \pm 4.05$ and $0.71 \pm 1.51$ vs. $0.79 \pm$ 2.08 respectively (Table-I).

Table I. Comparison of demographic features \& FRAX predicted 10 -year risk scores among male \& female subjects $(\mathrm{n}=600)$.

\begin{tabular}{lccc}
\hline Variables & $\begin{array}{c}\text { Male } \\
\text { Mean } \pm \text { SD }\end{array}$ & $\begin{array}{c}\text { Female } \\
\text { Mean } \pm \text { SD }\end{array}$ & $\begin{array}{c}\mathrm{p} \\
\text { value }\end{array}$ \\
\hline Age(Yrs) & $52.91 \pm 8.20$ & $51.08 \pm 7.50$ & $<0.01$ \\
Height $(\mathrm{m})$ & $1.62 \pm 7.36$ & $1.53 \pm 6.88$ & $<0.001$ \\
Weight $(\mathrm{kg})$ & $65.64 \pm 7.64$ & $60.36 \pm 8.29$ & $<0.001$ \\
BMI $\left(\mathrm{kg} / \mathrm{m}^{2}\right)$ & $24.70 \pm 2.76$ & $25.58 \pm 3.79$ & .001 \\
FRAX 10-year Risk Scores: & & \\
Major osteoporotic & $2.64 \pm 2.64$ & $3.28 \pm 4.05$ & $<0.02$ \\
fracture: & & & \\
Hip fracture: & $0.71 \pm 1.51$ & $0.79 \pm 2.08$ & $<0.59$ \\
\hline
\end{tabular}

Among female subjects, $69.23 \%$ were post-menopausal and $30.76 \%$ were not post-menopausal. BMI $\left(\mathrm{kg} / \mathrm{m}^{2}\right)$ was significantly higher in post menopausal group than non-menopausal group $(25.99 \pm 3.83$ vs. $24.54 \pm 3.53$; $\mathrm{p}<0.05$ ). FRAX predicted 10 -year risk scores of both major osteoporotic fracture and hip fracture showed significant association with post menopausal group than compared with non-menopausal group ( $3.91 \pm 4.59$ vs. $1.78 \pm 1.66 ; \mathrm{p}<0.05 \& 1.06 \pm 2.45$ vs. $0.17 \pm 0.20$; $\mathrm{p}<0.05) \quad($ Table-II).

Table II. Comparison of demographic features \& FRAX predicted10-year risk scores among female subjects (Post menopausal \& non-menopausal group)

\begin{tabular}{lccc}
\hline Variables & \multicolumn{2}{c}{ Female } & $\mathrm{p}$ \\
& $\begin{array}{c}\text { Post } \\
\text { Menopausal } \\
\text { Mean } \pm \text { SD }\end{array}$ & $\begin{array}{c}\text { Menopausal } \\
\text { vean } \pm \text { SD }\end{array}$ & \\
& $54.71 \pm 6.00$ & $42.86 \pm 1.97$ & $<0.001$ \\
& $1.53 \pm 7.15$ & $1.54 \pm 6.26$ & $<0.001$ \\
\hline Age(Yrs) & $61.32 \pm 8.31$ & $57.97 \pm 7.66$ & $<0.001$ \\
Height $(\mathrm{m})$ & $25.99 \pm 3.83$ & $24.54 \pm 3.53$ & $<0.001$ \\
Weight $(\mathrm{kg})$ & & &
\end{tabular}

FRAX 10-year Risk Scores:

Major osteoporotic $3.91 \pm 4.59 \quad 1.78 \pm 1.66<0.001$ fracture:

\begin{tabular}{llll} 
Hip fracture : & $1.06 \pm 2.45$ & $0.17 \pm 0.20$ & .001 \\
\hline
\end{tabular} 
Risk Assessment Factors for FRAX predicted 10year Risk Scores among Study Subjects.

Risk assessment factors for FRAX predicted10-year risk scores among male and female did not differ significantly (Table III). Those factors also did not differ significantly in between post-menopausal and non menopausal groups of female subjects (Table IV). Among study subjects, those who had risk assessment factors i.e. family history of fractured hip, glucocorticoids, rheumatoid arthritis showed significant association with presence of both 10year risk scores of $\geq 20 \%$ for major osteoporotic fracture $(p<0.05)$ and $\geq 3 \%$ for hip fracture $(p<0.05)$, and those who had risk assessment factors i.e. history of previous fracture, secondary osteoporosis showed significant association only with FRAX predicted 10 -year risk scores of $\geq 3 \%$ for hip fracture $(p<0.05)$. (Table V \& Table VI).

Table III. Prevalence of risk assessment factors for FRAX predicted10-year risk scores among male \& female subjects. $(\mathrm{n}=600)$

\begin{tabular}{|c|c|c|c|c|c|c|}
\hline \multirow[t]{2}{*}{ Risk assessment factors } & & \multicolumn{2}{|c|}{ No } & \multicolumn{2}{|c|}{ Yes } & \multirow{2}{*}{$\begin{array}{c}\mathrm{p} \\
\text { value }\end{array}$} \\
\hline & & $\mathrm{n}$ & $\%$ & $\mathrm{n}$ & $\%$ & \\
\hline \multirow[t]{2}{*}{ Previous fracture: } & Male & 288 & 58.06 & 65 & 62.50 & .403 \\
\hline & Female & 208 & 41.93 & 39 & 37.50 & \\
\hline \multirow[t]{2}{*}{ Parent fractured hip: } & Male & 293 & 58.60 & 60 & 60.0 & .795 \\
\hline & Female & 207 & 41.40 & 40 & 40.0 & \\
\hline \multirow[t]{2}{*}{ Current smoking: } & Male & 167 & 40.63 & 186 & 98.41 & $<0.001$ \\
\hline & Female & 244 & 59.36 & 3 & 1.58 & \\
\hline \multirow[t]{2}{*}{ Glucocorticoids: } & Male & 309 & 60.35 & 44 & 50.0 & .068 \\
\hline & Female & 203 & 39.64 & 44 & 50.0 & \\
\hline \multirow[t]{2}{*}{ Rheumatoid arthritis: } & Male & 282 & 58.87 & 71 & 58.67 & .969 \\
\hline & Female & 197 & 41.12 & 50 & 41.32 & \\
\hline \multirow[t]{2}{*}{ Secondary osteoporosis: } & Male & 312 & 60.11 & 41 & 50.61 & .106 \\
\hline & Female & 207 & 39.88 & 40 & 49.38 & \\
\hline
\end{tabular}

N.B: chi-square test was done. $\mathrm{p}<0.05$ was considered as significant.

Table IV. Comparison of frequency of risk assessment factors for FRAX predicted10-year risk scores among post menopausal \& non-menopausal female subjects. $(n=247)$

\begin{tabular}{|c|c|c|c|c|c|}
\hline \multirow[t]{2}{*}{ Risk Assessment Factor } & \multicolumn{2}{|c|}{ No } & \multicolumn{2}{|c|}{ Yes } & \multirow{2}{*}{$\begin{array}{c}\mathrm{p} \\
\text { value }\end{array}$} \\
\hline & $\mathrm{n}$ & $\%$ & $\mathrm{n}$ & $\%$ & \\
\hline \multicolumn{6}{|l|}{ Previous fracture: } \\
\hline Post menopausal & 147 & 29.63 & 24 & 61.53 & .388 \\
\hline Non-menopausal & 61 & 12.29 & 15 & 38.46 & \\
\hline \multicolumn{6}{|l|}{ Parent fractured hip: } \\
\hline Post menopausal & 144 & 28.80 & 27 & 67.50 & \\
\hline Non-menopausal & 64 & 12.80 & 12 & 30.0 & \\
\hline \multicolumn{6}{|l|}{ Current smoking: } \\
\hline Post menopausal & 169 & 41.11 & 2 & 66.66 & $<0.001$ \\
\hline Non-menopausal & 75 & 18.24 & 1 & 33.33 & \\
\hline \multicolumn{6}{|l|}{ Glucocorticoids: } \\
\hline Post menopausal & 141 & 27.53 & 30 & 68.18 & .187 \\
\hline Non-menopausal & 62 & 12.10 & 14 & 31.81 & \\
\hline \multicolumn{6}{|l|}{ Rheumatoid arthritis: } \\
\hline Post menopausal & 137 & 28.60 & 34 & 68.0 & .977 \\
\hline Non-menopausal & 60 & 12.52 & 16 & 32.0 & \\
\hline \multicolumn{6}{|l|}{ Secondary osteoporosis: } \\
\hline Post menopausal & 146 & 28.13 & 25 & 62.50 & .150 \\
\hline Non-menopausal & 61 & 11.35 & 15 & 37.50 & \\
\hline
\end{tabular}

N.B.: chi-square test was done. $\mathrm{p}<0.05$ was considered as significant. 
Table V. Association of risk assessment factors with risk scores for $\geq 3 \%$ for hip fracture among subjects.

\begin{tabular}{|c|c|c|c|}
\hline \multirow[t]{2}{*}{$\begin{array}{l}\text { Risk Assessment } \\
\text { Factors }\end{array}$} & \multicolumn{2}{|c|}{$\begin{array}{c}\text { Risk scores } \geq 3 \% \\
\text { for hip fracture }\end{array}$} & \multirow[t]{2}{*}{$\begin{array}{c}\mathrm{p} \\
\text { value }\end{array}$} \\
\hline & $\mathrm{n}$ & $\%$ & \\
\hline \multicolumn{4}{|l|}{ Previous fracture: } \\
\hline Present & 14 & 37.50 & $<0.001$ \\
\hline Absent & 16 & 3.22 & \\
\hline \multicolumn{4}{|c|}{ Parent fractured hip: } \\
\hline Present & 18 & 18.0 & $<0.001$ \\
\hline Absent & 12 & 2.40 & \\
\hline \multicolumn{4}{|l|}{ Current smoking: } \\
\hline Present & 11 & 5.82 & 0.532 \\
\hline Absent & 19 & 4.62 & \\
\hline \multicolumn{4}{|l|}{ Glucocorticoids: } \\
\hline Present & 15 & 17.04 & $<0.001$ \\
\hline Absent & 15 & 2.92 & \\
\hline \multicolumn{4}{|c|}{ Rheumatoid arthritis: } \\
\hline Present & 14 & 11.57 & $<0.001$ \\
\hline Absent & 16 & 3.34 & \\
\hline \multicolumn{4}{|c|}{ Secondary osteoporosis: } \\
\hline Present & 8 & 9.87 & $<0.05$ \\
\hline Absent & 22 & 4.23 & \\
\hline
\end{tabular}

N.B.: chi-square test was done. $p<0.05$ was considered as significant.

\section{Discussion}

Osteoporosis is mainly known as the disease of postmenopausal women. ${ }^{10}$ As the greatest loss of bone mass occurs in women during perimenopause and is associated with estrogen insufficiency; a condition of menopause. ${ }^{5}$ Osteoporotic fracture refers to fractures that result from mechanical forces as little as minor compression that would not ordinarily result in fracture. It is an important condition in terms of health and economic aspects because it increases total medical expenditures. ${ }^{11}$ The risk factors of osteoporotic fracture include old age, previous history of fracture, use of steroids, parental history of hip fracture, low weight, excessive alcohol intake, rheumatoid arthritis and secondary osteoporosis. Among them, age, past history of fracture and low BMD are known as the strongest risk factors for the likelihood of fracture. ${ }^{12,13}$ Therefore, it is incumbent upon the clinical practitioner to identify patients in whom treatment will result in the greatest benefit while avoiding treatment of low-risk individuals
Table VI. Association of risk assessment factors with risk scores for $\geq 20 \%$ for major osteoporotic fracture

Risk Assessment Risk scores $\geq 20 \%$ for $p$

Factors major osteoporotic fracture value

\begin{tabular}{llll} 
& $\mathrm{n}$ & $\%$ & \\
\hline $\begin{array}{l}\text { Previous Fracture: } \\
\quad \text { Present }\end{array}$ & 1 & 0.96 & 0.684 \\
$\quad$ Absent & 3 & 0.80 & \\
Parent fractured hip: & & & \\
$\quad$ Present & 3 & 3.0 & $<0.01$ \\
$\quad$ Absent & 1 & 0.20 & \\
Current smoking: & & & \\
$\quad$ Present & 1 & 0.52 & 0.779 \\
$\quad$ bsent & 3 & 0.72 & \\
Glucocorticoids: & & & \\
$\quad \begin{array}{l}\text { Present } \\
\text { Absent }\end{array}$ & 2 & 2.27 & $<0.05$ \\
Rheumatoid arthritis: & 2 & 0.39 & \\
$\quad$ Present & 3 & & \\
$\quad$ Absent & 1 & 0.20 & \\
Secondary osteoporosis: & & & \\
$\quad$ Present & 1 & 1.23 & 0.499 \\
$\quad$ Absent & 3 & 0.57 & \\
\hline
\end{tabular}

N.B: chi-square test was done. $\mathrm{p}<0.05$ was considered as significant.

where the expectation of benefit is small. The FRAX, developed by the WHO Collaborating Centre for Metabolic Bone Diseases, allows for the estimation of individual fracture risk based upon that individual's risk factor profile. ${ }^{11}$ The adoption of 10 -year fracture risk reporting in clinical practice has been shown to beneficial impact on prescribing practices by physicians through better alignment of treatment initiation with the patient's actual risk when compared with a BMD T-score alone. ${ }^{12}$ Not with standing the substantial impact of FRAX on clinical practice and its increasing use in clinical practice guidelines, ${ }^{8,13-15}$ questions remain on how to improve FRAX and better inform those who use FRAX in clinical practice. FRAX model's usefulness had been verified by several studies so far. However, the intervention threshold for osteoporosis is not yet established. ${ }^{12,13}$ Now, under the auspices of the National Osteoporosis Guideline Group, 10 professional bodies and patients' organizations have developed an 
evidence-based management guideline for both men and postmenopausal women aged over $50 .{ }^{16}$ NOFG recommends treating patients with FRAX 10-year risk scores of $\geq 3 \%$ for hip fracture or $\geq 20 \%$ for major osteoporotic fracture, to reduce their fracture risk ${ }^{9}$. NOFG acknowledges the view that treatment should not be offered in the absence of BMD measurement except to women who have already had a fragility fracture. ${ }^{16}$

In present study, the mean BMI of study subjects presented significant differences between male and female $(\mathrm{p}<0.05)$. The mean FRAX predicted 10-year risk scores of major osteoporotic fracture were more significant in female subjects $(\mathrm{p}<0.02)$. Risk assessment factors for FRAX predicted 10-year risk scores did differ significantly neither among male and female nor among post menopausal and non-menopausal subjects. FRAX 10-year risk scores of both major osteoporotic fracture and hip fracture showed significant association among post menopausal women than non-menopausal group $(\mathrm{p}<0.05)$. According to NOFG recommendation, the frequency FRAX 10-year risk scores of $\geq 3 \%$ for hip fracture or $\geq 20 \%$ for major osteoporotic fracture among different study groups were calculated. Among subjects, those who had risk assessment factors i.e. history of parent fractured hip, glucocorticoids, rheumatoid arthritis showed significant association with presence of both risk scores of $\geq 20 \%$ for major osteoporotic fracture and $\geq 3 \%$ for hip fracture $(p<0.05)$. And those who had risk factors i.e. history of previous fracture, secondary osteoporosis showed only significant association with risk scores of $\geq 3 \%$ for hip fracture $(\mathrm{p}<0.05)$. Those patients who had FRAX predicted 10 year risk scores of $\geq 3 \%$ for hip fracture or $\geq 20 \%$ for major osteoporotic fracture were counseled properly and advised for DEXA scan to measure their BMD scores before starting treatment.

\section{Conclusion}

This study suggests that FRAX has the potential to determine fracture risk assessment in primary care for patients. It is validated to be used in undiagnosed patients only and may have value for guiding the need for treatment. By noting down the risk factors, we can screen out the subjects both male and female who require further evaluation and management. It is an effective tool, particularly in developing countries like Bangladesh, where most of the patients cannot afford expensive DEXA scans. FRAX will help clinicians not only to identify individuals who need osteoporosis treatments, but also screening out those who do not require osteoporosis treatments.

Conflict of interest: Nothing to declare.

\section{Acknowledgement}

Dr. Parvin Akter Khanam, Associate Professor, Department of Epidemiology and Biostatistics, BIRDEM General Hospital.

\section{References}

1. Oleksik A, Lips P, Dawson A, John K. Health related quality of life in postmenopausal women with low BMD with or without prevalent vertebral fractures. J Bone Miner Res 2000;15:1384-92.

2. Fechtenbaum J, Cropet C, Kolta S, Roux C. The severity of vertebral fractures and health related quality of life in osteoporotic postmenopausal women. Osteoporos Int 2005;16:2175-79.

3. Kado DM, Browner WS, Palermo L, Nevitt Mc, Genant HK, Cummings SR. Vertebral fractures and mortality in older women: a prospective study. Arch Intern Med 1999; 159:121520.

4. Kado DM, Duong T, Stone KL, Ensrud KE, Nevitt MC, Grundale GA, et al. Incident vertebral fractures and mortality in older women: a prospective study. Osteoporos Int 2003;14: 589-94.

5. Prevention and management of osteoporosis. Geneva: World Health Organization; 2003. World Health Organization Scientific Group on the Prevention and Management of Osteoporosis. (Technical Report Series, 921)

6. Nordin BE. International patterns of osteoporosis. Clin Orthop 1966;45:17-30.

7. Siris E.S, Miller PD, Barrnett-Connor E, Faulkner KG, Wehren LE, Abott TA, et al. Identification and fracture outcomes of undiagnosed low bone mineral density in postmenopausal women. Results from the National Osteoporosis Risk Assessment. JAMA 2001; 286:2815-22.

8. Kanis JA. On behalf of the WHO Scientific Group. Assessment of osteoporosis at the primary health care level. Technical Report. Sheffield, WHO Collaborating Centre, University of Sheffield,UK.(www.shef.ac.uk/FRAX) 2008.

9. Siris E S, Baim S, Nattiv A. Primary care use of FRAX: absolute fracture risk assessment in postmenopausal women and older men. Post grad Med 2010; 122:82-90.

10. Osteoporosis prevention, diagnosis, and therapy. NIH Consensus Development Panel on Osteoporosis Prevention, Diagnosis, and Therapy. JAMA2001;85:785-95.

11. Margaret L. Gourlay W C. Miller FRJ, Garrett M, Laura C. Hanson JR. Performance of osteoporosis risk assessment tools in postmenopausal women aged 45-64 years. Osteoporos Int 2005;16:921-27. 
12. Nayak S, Edward DL, Saleh AA, Greenspan S. Performance of risk assessment for predicting osteoporotic fracture: a systematic review. Osteoporos Int 2013.

13. Fujiwara S, Nakamura T, Orimo H, Hosoi T, Gorai I, Oden A et al. Development and application of a Japanese model of the WHO fracture riskassessment tool (FRAXTM). Osteoporos Int 2008;19:429-35.

14. Grados F, Fechtenbaum J, Flipon E, Kolta S, Roux C, Fardellone P. Radiographic methods for evaluating osteoporotic vertebral fractures. Joint Bone Spine 2009; 241-47.

15. Gadam RK, Schlauch K, Izuora KE. Frax Prediction without BMD for Assessment of Osteoporotic Fracture Risk. Endocr Pract 2013;19:780-84.

16. National Osteoporosis Guideline Group. Guideline for the diagnosis and management of osteoporosis in postmenopausal women and menfrom the age of 50 years in the UK. October 2008(www.shef.ac.uk/NOGG/NOGG_Pocket_Guide_for_ Healthcare_Professionals.pdf; accessed 14.10.08). 